\title{
ARE BURROWING OWLS USING ENHANCED HABITAT?
}

ANDREA KOTYLAK and MARGARET A. SKEEL, Nature Saskatchewan, 206 - 1860 Lorne Street, Regina, SK, S4P 2L7

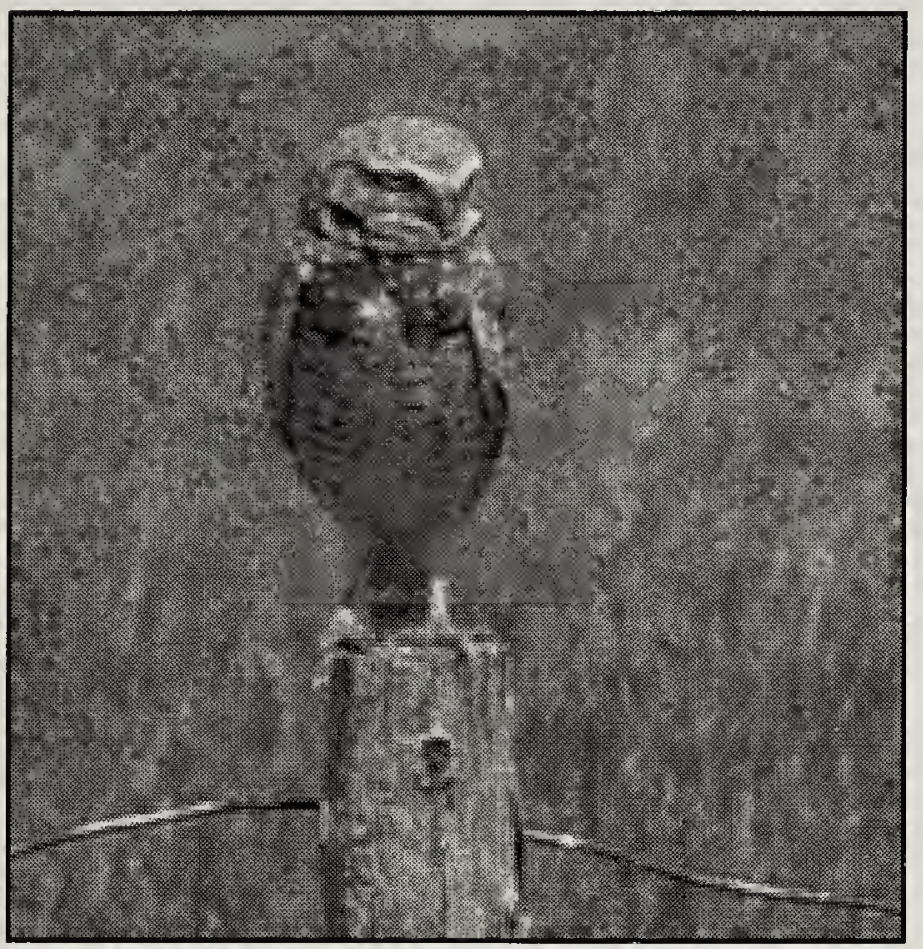

Burrowing owl perched on a fence post. This photo was taken in the summer of 2009, 1/4 mile east of McCord, SK. There were 4 owlets and the parents, one of which is shown here. On one occasion, one of the parents was seen chasing a badger across the road away from the nest. Gail Peterson

Through Operation Burrowing Owl (OBO), Nature Saskatchewan (NS) delivers a habitat enhancement program focusing on improving habitat for the endangered Burrowing Owl to aid in its recovery. Monitoring at OBO sites has indicated that the Saskatchewan Burrowing Owl population has declined by 92\% from 1988 to 2009 (OBO database). Habitat is improved by enlarging pastures to increase grassland patch size and reduce habitat fragmentation. From 2000 to 2008 , funding assistance was provided to landowners on a 50:50 cost share basis to seed cultivated land adjacent to existing grassland to perennial grass, with seven invasive tame species excluded from seed mixes (Smooth Bromegrass [Bromus inermis], Crested Wheatgrass [Agropyron sp.], Quack Grass [A. repens], Kentucky Bluegrass [Poa pratensis], Timothy [Phleum pratense], Reed Canary grass [Phalaris arundinacea], and Sweet Clover [Melilotus alba]). Project sites were required to be nearby (usually within 5 $\mathrm{km}$ ) to pastures that supported Burrowing Owls within the past 20 years with priority given to sites that housed owls within the past 3 years, as verified by the OBO database. Each year, OBO landowners report the number of owl pairs and singles on their land, including those on the enhanced sites, through a mail-in census card or through being contacted by $\mathrm{OBO}$. The National Burrowing Owl Recovery Team endorses habitat enhancement as an important recovery action on the breeding grounds. ${ }^{1}$

There was sufficient interest by rural landowners in the program from 2000 to 2006 to complete 85 projects that saw the conversion of 4849 ha (11,983 acres) of cropland to perennial grass. Each project is all or a portion of a quarter section (64.7 ha or 160 acres). When only a portion of a quarter section was converted, the remaining area usually was already pasture or hayland. In 2007, we examined the program to determine whether project sites or adjacent pastures were being used by Burrowing Owls and other prairie birds and mammals.

\section{Site Selection}

We selected habitat enhancement project sites based on age, location, and recent reports of owls in the area. Of the 57 project sites that were seeded from 
2000 to 2004 and thus had been seeded for at least 2 years (allowing time for the grass to establish), 10 were selected. These 10 sites were chosen from among 16 project sites at least 2 years old and within the Regina Plain (K17) and adjacent Dirt Hills (M19) and Griffin Plain (K18) landscape areas; these areas tend to support higher owl numbers than other areas (OBO database). The remaining six project sites that met the age and location criteria had no recent owl activity and thus were excluded from the study due to limited resources.

The study was comprised of 28 quarter sections: 10 project sites along with 18 adjacent quarter sections with native or tame pasture or hayland. Adjacent pastures were surveyed, as owls may be using or attracted by the project site and may be nesting nearby. For three of the project sites, only a portion of the quarter section was in grassland. Adjacent quarter sections that were cultivated land (cropland or summer fallow) were not surveyed, as these were not suitable habitat, but the roadside habitat next to these areas was searched. For two sites, we were aware of owl activity in 2007 prior to our study, as these were reported by the landowner at one site and another researcher at the other (R. Poulin, Royal Saskatchewan Museum, pers. comm.) that was part of his Regina Plain study. When contacted to request permission to survey their land, the landowners of the 28 sites provided us with information on current ground cover (crop vs. pasture), presence of ground squirrels and/or badgers, and if they had seen Burrowing Owls on the quarter section in the current or previous years. Through these contacts, we were informed of owls currently on a quarter section adjacent to a habitat enhancement project site.

\section{Survey Methodology}

Four NS staff worked in pairs to conduct surveys on foot in intervals of $100 \mathrm{~m}$, observing $50 \mathrm{~m}$ on each side of the surveyor. On occasion, surveys deviated from a straight line to ensure thorough coverage of the most suitable habitat, including areas with badger or ground squirrel burrow presence. Areas of unsuitable owl habitat (vegetation higher than $75 \mathrm{~cm}$ and extremely dense) were not surveyed. For each site, the surveyor recorded GPS coordinates of detections (by sight or sound) of Burrowing Owls, nine other grassland bird species, badger or ground squirrel holes by abundance category (category 1: one hole per cluster, category 2: two to four holes per cluster and category 3: more than five holes per cluster) as these are potential nest sites for Burrowing Owls, and all temporary or permanent wetlands.

Surveys were conducted from 25 June to 10 July 2007, when owls and their broods were most visible due to young owls around nest entrances and there was increased activity from fledglings learning to hunt and fly. ${ }^{2}$ Failed nests may have been missed during these surveys. Surveyors looked for signs of an active burrow (nest site): a well-trampled mound outside the burrow; a burrow entrance that is scattered with owl pellets, bones, and/ or insect parts; shredded manure in and whitewash (owl excrement) surrounding the burrow entrance; and the presence of Burrowing Owls. Sites with nesting owls were revisited from 23 July to 3 August to identify nests that successfully fledged young as indicated by their presence near the nest hole.

\section{Results and Discussion}

As considerable effort has gone into habitat enhancement for Burrowing Owls since 2000 , we investigated whether there was evidence of owl use of project sites by checking the most likely project sites that owls might be using. Our study provides evidence that owls will use 
project sites or may be attracted to areas adjacent to these, and that it may be a number of years before this occurs.

We observed a total of five pairs (all nests fledged young) and 11 single Burrowing Owls on six of the 28 quarter sections that comprised the study. Of the 10 quarter sections with project sites, owls were found nesting on three. However, only one of the three quarter sections had owls nesting on the project site, and the other two had owls nesting on the native grass portion of the quarter section. The project site with nesting owls included one pair and two single young (140 acres seeded to grassland: 40 acres in 2000 , 75 acres in 2001, and 25 acres in 2003). Of the two quarter sections with nesting owls on the native grass portion, one had two nesting pairs and four single owls (15 acres seeded in 2000; not a full quarter in grassland), and the other had one adult (200 acres seeded in 2000).

Burrowing Owls were found on three of the 18 quarter sections adjacent to project site quarter sections. One of these (mixed grassland) supported one pair and one single adult. The other two were adjacent to the same project site quarter section, with one (native grass) supporting one pair and a single adult and the other (a stubble field, surveyed as it had not been seeded) with two single adults.

Of the 28 quarter sections in the study, three had many more clusters ( $>40$ clusters) of ground squirrel holes in category 3 ( $>5$ holes in the cluster) than the others (with $<15$ clusters). The three quarter sections with many holes supported one to two pairs of nesting owls, including the project site with one pair of owls. The fourth quarter section with nesting owls had fewer holes (six clusters in category 3 ), similar to quarter sections with no owls. Sixteen of the 28 quarter sections had only smaller clusters of holes and no clusters in category 3 , including four of the 10 project sites. These results reaffirm the need for sufficient numbers of burrows and burrowing mammals for owl occupancy of grassland habitat. ${ }^{3}$

Burrowing Owls were located on or adjacent to five of the 10 project sites, and were more often found on those with better established ground squirrel populations. The landowners of 24 of the 28 quarter sections in the study did not recall seeing owls prior to the enhancement projects, suggesting that at least some owls may have been there as a result of the project site providing or enhancing habitat. On the remaining four quarter sections, two with a project site had nesting owls every year on the native grass portion, and no information was available for two that were adjacent to project sites.

In addition, eight of the nine grassland bird species selected as representative species were found on quarter sections with project sites: Western Meadowlark (eight sites), Savannah Sparrow (seven sites), Horned Lark (five sites), Baird's Sparrow (four sites), Vesper Sparrow (three sites), Bobolink (three sites), Clay-coloured Sparrow (two sites), and Sprague's Pipit (two sites). Loggerhead Shrikes were not found at any sites, although one individual was recorded on an adjacent quarter section. The 10 quarter sections with project sites were used to varying degrees with each site used by at least one of the nine grassland bird species and four sites used by five species.

In 2008 and 2009, the annual OBO census indicated further encouraging results, bringing the number of project sites used by nesting owls to five. Of the 120 projects (6173 ha or 15,254 acres seeded) that have been completed through 
NS across southern Saskatchewan from 2000 to 2008, Burrowing Owls were reported nesting on ten quarter sections with project sites (including on five project sites) in at least one year between 2007 and 2009; no owls were reported prior to 2007 . Single owls were reported on an additional three project site quarter sections.

In 2007, a nesting pair of owls was first reported on a project site (as noted above); in 2008 and 2009, no owls returned to the project site but two and three pairs, respectively, nested on the native portion of this quarter. In 2008, nesting pairs were reported on two different project sites: two pairs on a site seeded in 2000 (a single owl in 2007 and one pair in 2009), and one pair on a site seeded in 2005. In addition, a single owl was reported on a third project site. In 2009, nesting pairs were reported on three project sites: one pair on a site seeded in 2000 (same site with a single owl in 2007 and two pairs in 2008; in 2009 there were also two additional pairs on the native portion of this quarter section), one pair on a site seeded in 2006, and one pair on a site seeded in 2008. In addition, a single owl was reported on a fourth project site.

These results provide encouragement that enhanced sites will be used by owls as the sites become established. Given time for this to occur, further and more rigorous study of enhancement projects may reveal their importance in the recovery of the Saskatchewan Burrowing Owl population.

\section{Acknowledgements}

We thank B.J. MacDougall, R. Magnus (née West), and $M$. Yaskowich who assisted $A$. Kotylak with the field work, and $C$. Gaudet for helping with data management. Many thanks to $C$. Gaudet, R. Warnock, and an anonymous reviewer for comments on an earlier draft. We thank OBO program funders: Government of Canada Habitat Stewardship Program for Species at Risk, Saskatchewan Ministry of Environment - Fish \& Wildlife Development Fund, U.S Fish \& Wildlife Service Neotropical Migratory Bird Conservation Act, EJLB Foundation, SaskPower, World Wildlife Fund and Environment Canada - Endangered Species Recovery Fund, TD Friends of the Environment Foundation, ECO Canada - Environmental Youth Corps, Service Canada - Canada Summer Jobs and SaskCulture - Student Employment Experience.

1. ENVIRONMENT CANADA. 2007. Recovery Strategy for the Burrowing Owl (Athene cunicularia) in Canada [Proposed]. Species At Risk Act Recovery Strategy Series. Environment Canada, Ottawa, Ontario.

2. NATURE SASKATCHEWAN. 2009. Burrowing Owls in Saskatchewan: Living and Surviving on a Changing Prairie Landscape. Nature Saskatchewan, Regina, Saskatchewan.

3. WARNOCK, R. G. and M. A. SKEEL. 2002. Habitat features important to Burrowing Owl breeding success in Saskatchewan. Blue Jay 60:135-145.

CORRECTION: In the September 2009 issue of Blue Jay, p. 147, the top photo shows Cliff Wallis with Bill and Natalia Labatiuk. 